\title{
Era uma vez... \\ Um olhar sobre 0 uso dos contos de fada como ferramenta de educação alimentar e nutricional
}

Introdução

“... com muita fome e sede, Branca de Neve comeu de cada prato um pouco de verduras e pão e bebeu de cada caneca, um gole de vinho...". (Branca de Neve e os Sete Anões)

Ao nascer e entrar em contato com o novo mundo que a cerca, a criança está exposta a estímulos de toda natureza. É também nesse momento que entrará em contato com os alimentos e iniciará o processo de estabelecimento de hábitos alimentares que podem perdurar por toda a vida.

Inicialmente, a família representa o principal fator de influência sobre o padrão alimentar das crianças. Responsáveis pela oferta de alimentos, a atitude que os pais adotam diante do alimento pode afetar, significativamente, o desenvolvimento desses hábitos. O processo inicia-se no aleitamento, com a formação do vínculo mãe-filho, progride durante a introdução alimentar, e é, posteriormente, afetado, pela disponibilidade de alimentos, o modelo que os pais representam e os mecanismos de controle que adotam em relação às práticas alimentares (autoritário, autoritativo, permissivo, negligente), e que incluem o uso de estímulos positivos ou negativos (Bowne, 2009; Cullen et al., 2001; Birch, 1998).

Com o ingresso da criança na escola, o processo passa a sofrer maior influência do meio: a criança realiza refeições fora de casa (alimentação escolar, compra na cantina), o alimento passa a ter outra representação social importante (amigos), e o ambiente escolar torna-se a principal fonte de conhecimento formal sobre nutrição.

A escola oferece inúmeras oportunidades para ações de promoção de educação em saúde, pois propicia situações de aprendizagem para um amplo setor da população. Tais ações se iniciam desde a entrada das crianças na escola e perduram por todos os anos acadêmicos, garantindo o tempo e a intensidade necessários para as intervenções. Além disso, as ações na escola ainda permitem a articulação com a família e a comunidade (Peréz-Rodrigo, Aranceta, 2001).

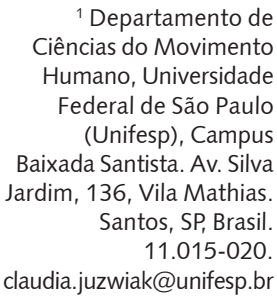

$$
\begin{aligned}
& { }^{2} \text { Trecho traduzido de } \\
& \text { GRIMM, J.K. The } \\
& \text { household tales by } \\
& \text { Brothers Grimm. Trad. } \\
& \text { Margaret Hunt. Londres: } \\
& \text { London G Bell \& Sons, } \\
& \text { 1910. Disponível em: } \\
& \text { <http:// } \\
& \text { www.gutenberg.org/ } \\
& \text { ebooks/5314>. }
\end{aligned}
$$




\section{Educação Alimentar e Nutricional (EAN) e a escola}

"E quando houve uma grande carência na terra, nenhum homem conseguia ganhar o suficiente para o pão diário". (João e Maria) ${ }^{3}$

Recentemente, a publicação da Portaria Interministerial no 1010 (Brasil, 2006), da Resolução do Fundo Nacional de Desenvolvimento da Educação - FNDE n 38 (Brasil, 2009a), e a sanção da Lei 11.947 (Brasil, 2009b) representaram um marco no processo de fortalecimento das ações de EAN dentro da perspectiva de políticas públicas. Estas iniciativas instituíram diretrizes para a promoção da alimentação saudável nas escolas públicas e privadas, em consonância com a Política de Alimentação e Nutrição, e como parte do Programa Nacional de Alimentação Escolar - PNAE, prevendo a "incorporação do tema alimentação saudável no projeto político pedagógico da escola, perpassando todas as áreas de estudo e propiciando experiências no cotidiano das atividades escolares" (Brasil, 2006, p.70). Nesses documentos são sugeridas estratégias para a implementação da EAN que incluem: a oferta da alimentação saudável na escola, a implantação e manutenção de hortas escolares pedagógicas, a inserção do tema alimentação saudável no currículo escolar, a realização de oficinas culinárias experimentais, a formação da comunidade escolar, bem como o desenvolvimento de tecnologias sociais que a beneficiem.

Observa-se uma tendência em concentrar o tema alimentação e nutrição nas aulas de ciências, privilegiando o enfoque biológico (Soares, Lazzari, Ferdinandi, 2009; Pipitone et al., 2003) e distanciando-se do papel social e cultural do alimento, assim como das situações de vivência. Boog (2008) reforça que o ensino sobre alimentação e nutrição não deve ser restrito a essa disciplina ou a um determinado período do ano letivo, ou trabalhado em projetos específicos, uma vez que alimentar-se constitui prática do cotidiano.

Bizzo e Leder (2005) enfatizam pontos essenciais que devem caracterizar a metodologia pedagógica da EAN na escola: além da importância dos temas a serem tratados de forma transversal é fundamental privilegiar o diálogo horizontal, respeitando o conhecimento e a cultura. Outras características ressaltadas por essas autoras dizem respeito à necessidade de as ações propostas terem significado para os estudantes, serem problematizadoras, propositivas e cultivarem a construção da cidadania. O seu sucesso depende do grau de integração de todas as áreas de conhecimento e com o serviço de alimentação, e deve ser reforçada pelas experiências alimentares em casa (Brasil, 2006).

Crianças em idade pré e escolar apresentam grande desafio em termos de EAN, pois é necessário que sejam adotados estratégias e materiais que captem seu interesse, estimulem a participação e a aquisição de conhecimento, levando à adoção de comportamentos saudáveis, ao mesmo tempo em que sejam adequados à capacidade cognitiva e fase de desenvolvimento (Başkale et al., 2009).

Para este grupo é interessante selecionar atividades que enfatizem o aprender fazendo, um dos quatro pilares da educação propostos pela Unesco (Delors et al., 1999). O lúdico tem um papel fundamental, pois permite explorar o "aprender brincando", ressaltando-se que a brincadeira é um ato natural deste período. A brincadeira estimula o desenvolvimento infantil e facilita a aprendizagem, pois a própria motivação da criança é aproveitada, tornando a tarefa mais atrativa, enquanto o conhecimento vai sendo construído a partir de: estímulo dos sentidos, valorização da cultura, desenvolvimento motor, socialização e interação, exercício da imaginação e criatividade, e sistematização das experiências (Cordazzo, Vieira, 2007; Dallabona, Mendes, 2004).
${ }^{3}$ Trecho traduzido de GRIMM, J.K. The household tales by Brothers Grimm. Trad. Margaret Hunt. Londres: London G Bell \& Sons, 1910. Disponível em: $<$ http://www. gutenberg.org/ebooks/ 5314>. 
${ }^{4}$ Traduzido do inglês rampion. Este tipo de nabo, cujo nome científico é Campanula rapunculus, também é conhecido como Rapunzel em alguns países. As folhas e as raízes são comestíveis.

${ }^{5}$ Trecho traduzido de GRIMM, J.K. The household tales by Brothers Grimm. Trad. Margaret Hunt. Londres: London G Bell \& Sons, 1910. Disponível em: $<$ http://www.

gutenberg.org/ebooks/ 5314>.
Dentre as possibilidades de atividades que podem ser desenvolvidas, inclui-se a utilização de histórias infantis, sendo o objetivo deste texto refletir sobre as possibilidades de seu uso, em particular dos contos tradicionais, como instrumento de EAN para pré e escolares.

\section{Histórias infantis}

"A mulher estava na janela olhando o jardim abaixo, quando viu um canteiro plantado com os nabos ${ }^{4}$ mais lindos. Pareciam tão frescos e verdes que ela os desejou tanto, que sua maior vontade era comer alguns". (Rapunzel) ${ }^{5}$

Aguiar (2001), a partir da definição de vários autores, resume a literatura infantil como um gênero que utiliza vocabulário adequado e deve estar de acordo com a capacidade cognitiva e psíquica da faixa etária, divertindo ao mesmo tempo em que agrega novos aspectos do conhecimento, que satisfaçam a necessidade de experiência e ampliem a imaginação dos leitores.

"A literatura infantil [...] é uma porta para a experimentação de um mundo novo por meio da palavra e da imaginação" (Avellar, Couto, 2009, p.31). As histórias permitem o jogo com as palavras e as imagens, e divertem, enquanto a criança assimila a cultura e desenvolve a crítica, reflexão e a familiaridade com a escrita, e, ao serem lidas várias vezes, dão tempo para que os conceitos sejam fixados (Doran, 2005; Rodari, 2004). As histórias podem ser trabalhadas usando-se diversas estratégias, como: dramatização, contador de histórias e músicas, e, a partir de um tema central, muitos outros conteúdos podem ser desenvolvidos.

Um dos critérios para a classificação das histórias infantis considera a sua estrutura. Assim, segundo Aguiar (2001), há a lenda, um relato de caráter maravilhoso, poético ou modificado pela imaginação popular. O rico folclore brasileiro apresenta muitas lendas, como o Saci-Pererê, Curupira etc.; o mito, que vem da mitologia e está geralmente ligado à imagem de deuses gregos e outras figuras heroicas. Monteiro Lobato trouxe esses personagens para sua narrativa na aventura da turma do sítio do Pica-Pau Amarelo, na Grécia Antiga, acompanhando o semideus Hércules, na realização dos seus 12 trabalhos. A lenda e o mito foram criados na tentativa de o ser humano explicar fenômenos naturais; a fábula, uma ficção breve e de caráter alegórico, sempre apresenta uma lição moral. Caracteristicamente, os personagens principais são animais. Esopo e La Fontaine são autores clássicos deste tipo de histórias; e o apólogo também é de cunho moralista, mas traz objetos personificados no lugar de animais. Já os contos tradicionais/de fadas apresentam seres, objetos e lugares sobrenaturais, como bruxas, dragões, varinhas mágicas e feitiços. É comum que sejam apresentados com personagens e sentimentos opostos bem definidos, como "bem e mal", "confiança e traição". Apresentam mensagens, mas sem o mesmo peso moralista das fábulas.

Originários da Europa, estes contos, derivados da tradição oral, vêm atravessando os séculos e fronteiras. Sua forma literária e com fins educativos surgiu no final do século XVII, e, mesmo com as inúmeras adaptações, traduções e reproduções - livros, desenhos animados, filmes, discos/CD -, guardam a essência de suas mensagens (Ayob, 2010).

Os contos folclóricos e as fábulas eram originalmente contados por adultos e para adultos. Tinham como objetivo descrever costumes, crenças, hábitos e rituais, tribos e comunidades de um determinado período (Doran, 2005). Mesmo não refletindo a realidade do nosso século, os contos tradicionais são úteis para a 
formação das crianças, pois, a partir da reflexão que provocam, contribuem para que desenvolvam seu censo crítico (Lopes, 2010).

Os contos de fada estão suspensos no tempo e no espaço, situação caracterizada pelos tradicionais "era uma vez..." e "em um reino distante..." Apesar do nome, nem sempre há fadas nas histórias, que são substituídas por outros seres maravilhosos. Essas histórias só passaram a ser destinadas ao público infantil a partir do século XIX - Perrault, irmãos Grimm e Andersen publicaram os primeiros livros voltados a este público (Doran, 2005; Déhg, 1979).

O uso dos contos de fada na educação não é um consenso. Doran (2005), em revisão sobre o tema, discorre sobre pontos negativos e positivos deste uso a partir da posição de importantes pesquisadores do tema da área da psicologia e educação, como Bettelheim, Elkind e Montessori. Para os que se opõem à ideia, a maior crítica é para: o contato demasiado intenso com a fantasia, o medo que a criança possa desenvolver como resposta a situações comumente apresentadas nas histórias, a redução da imaginação devido à substituição da brincadeira imaginativa por brincadeira de imitação, e a exposição a estereótipos. Esses efeitos podem estar relacionados ao estágio de desenvolvimento da criança, pois, considerando os estágios propostos por Piaget, crianças no estágio préoperacional (cerca dos dois a sete anos) ainda não desenvolveram as estratégias necessárias para distinguir a fantasia da realidade, sendo sua capacidade de processar a informação estruturalmente limitada - é esta percepção irreal nesta fase que pode levar a criança a expressar medos irracionais ou novos, como o do abandono ou do ataque de monstros, ao ouvir os contos de fada cheios de bruxas, ogros e lobos.

Por outro lado, Doran (2005) resume pontos positivos: desenvolvimento do $i d$, resolução de elementos arquetípicos do desenvolvimento, fornecimento de modelos de resolução para problemas universais (morte, inveja, envelhecimento etc.), êxito do bem sobre o mal, e transmissão de comportamentos culturais dentro da construção da identidade ética, particularmente para crianças que já passaram para o estágio operacional concreto (Doran, 2005; Déhg, 1979).

\section{Alimentos, comensalidade e outras questões nutricionais nas histórias infantis}

“Um dia sua mãe disse - Venha Chapeuzinho Vermelho, aqui está um pedaço de bolo e uma garrafa de vinho. Leve para sua avó, ela está doente e fraca e será bom para ela". (Chapeuzinho Vermelho) ${ }^{6}$

No acervo de histórias infantis tradicionais, são encontradas várias situações relacionadas à alimentação que podem ser exploradas no ambiente escolar. A presença do alimento nas histórias é comum, pois representa o cotidiano.

Pensando na representação de alimentos e da comensalidade, é possível recordar inúmeras histórias tradicionais - a cesta de piquenique de Chapeuzinho Vermelho; o mingau dos três ursos, apreciado por Cachinhos Dourados; a casa de guloseimas, encontrada por João e Maria, e os banquetes nos finais felizes das princesas (Bunn, 2009).

Alguns estudos procuraram identificar a característica da representação dos alimentos nas histórias infantis e seu possível impacto, e sugerem que crianças podem ser influenciadas pelas situações mostradas e descobrem mecanismos de tomada de decisão e solução de problemas, melhorando sua autoestima (Byrne, Nitzke, 2002).

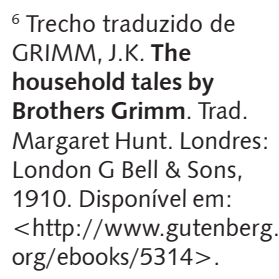


Em estudo norte-americano, Byrne e Nitzke (2000) avaliaram 114 livros de histórias infantis apropriados para escolares, com o objetivo de identificarem a presença e o tipo de mensagens sobre alimentos. Os resultados mostraram que $45 \%$ dos livros faziam, pelo menos, uma menção sobre alimentos, enquanto 13\%, cinco menções ou mais, totalizando 199 tipos de referências. Destas, 152 puderam ser classificadas segundo os grupos de alimentos da pirâmide alimentar, sendo que o mais mencionado foi o grupo dos grãos (21\%), seguido das frutas (20\%). A proporção de menções para os grupos açúcares simples/gorduras, carnes e lácteos foi de 19\%,16\% e 13\%, respectivamente. 0 grupo de hortaliças $(11 \%)$ foi menos mencionado do que os grãos e frutas $(p<0,05)$. Mensagens positivas, relacionando a alimentação com "divertimento, saúde, sabor e sinal de status econômico", foram mais frequentes $(77 \%)$ do que mensagens negativas, tais como "engordam, não gosto, não está fresco, não saudável" (11,5\%). Os autores avaliaram o envolvimento de personagens não humanos devido ao potencial efeito na força do modelo que estes seres exercem, e foram encontrados $66 \%$ animais e outros seres fantásticos.

O tipo de mensagem a que a criança é exposta parece influenciar a resposta ao alimento. Estudo com pré-escolares usou contos adaptados com mensagens sobre o consumo de hortaliças. Foram usadas mensagens positivas ("se você comer hortaliças, ficará saudável") ou negativas ("se você não comer hortaliças, ficará doente"), e, após a exposição à mensagem positiva, houve maior consumo do lanche oferecido à base de hortaliças no grupo, embora, em ambos os grupos expostos às mensagens, 0 consumo tenha sido maior do que no grupo controle (não exposto) (Lawatch, 1990).

Em uma série de experimentos, Almeida (2009) investigou se o comportamento de crianças de oito a 11 anos, após leitura de histórias, era dependente das contingências apresentadas. Após exposição a histórias sobre um garoto que come os doces da festa antes do seu início, com desfechos distintos (sem consequência vs. consequência aversiva), observou-se que, quando convidadas a preparar uma festa e deixadas em uma situação semelhante à da história, as crianças estudadas apresentaram mais comportamentos direcionados aos doces (olhar, tocar) após a história sem desfecho aversivo, embora em nenhuma situação tenha ocorrido o seu consumo.

As ilustrações também são importantes para o processo de aprendizagem, sobretudo no caso de crianças menores. Para crianças de dois a três anos, a interação social com o adulto que faz a leitura da história e que formula perguntas sobre as ilustrações e as rotula, cria oportunidades de aprendizagem. Tare et al. (2010) verificaram que, para crianças de 15 a vinte meses, quanto mais icônica a imagem em um livro (fotografias vs. desenhos), maior a sua posterior capacidade de identificação do objeto real.

A frequência a que somos expostos a estímulos, sejam auditivos, visuais, olfativos ou gustativos, pode provocar resposta positiva a um novo fator, por exemplo, a um alimento. Estudos com crianças de dois a cinco anos com neofobia indicam que a exposição de oito a 15 vezes a um mesmo alimento leva à sua aceitação (Birch, 1998). Ao usarem livros criados especificamente para um estudo com crianças de vinte a 27 meses, os quais foram lidos pelos pais, em experimentos com duração de uma a três semanas, Houston-Price et al. (2009) mostraram que a exposição às figuras de hortaliças e frutas afetou positivamente a resposta visual das crianças, quando reapresentadas às figuras a que estavam familiarizadas. Embora não tenha sido objeto do estudo, estes autores inferem, a partir dos seus resultados, que a exposição visual pode influenciar positivamente o futuro contato com o alimento.

Embora não esteja claro qual o impacto das mensagens sobre mudanças nos hábitos alimentares (Byrne, Nitzke, 2002), histórias infantis permitem o desenvolvimento de inúmeros conceitos sobre alimentos e nutrição (Evers, 2003). 


\section{Conteúdos relacionados à alimentação em contos de fada tradicionais}

\begin{abstract}
"Ele pensou 'Pelo menos semearei os feijões mágicos. Mamãe diz que são apenas feijões vermelhos comuns e nada mais; mas eu posso muito bem semeá-los'". (João e o Pé de Feijão) ${ }^{7}$
\end{abstract}

Alguns aspectos devem ser reforçados ao se trabalharem temas de alimentação e nutrição: é fundamental definir os conteúdos compatíveis com os objetivos que se pretendem alcançar, e a estrutura e desenvolvimento dos conteúdos devem ser adequados à capacidade cognitiva da faixa etária. Considerando os estágios de desenvolvimento propostos por Piaget, quanto mais jovem a criança, maior a dificuldade para compreender conceitos abstratos (ex: risco de doença, nutrientes), várias mensagens simultâneas ou complexas. A capacidade de classificar os alimentos, entender os processos corporais e como a alimentação afeta a saúde vai se solidificando conforme a criança desenvolve o processo mental até alcançar o pensamento adulto (Başkale et al., 2009).

Para que um currículo em educação em saúde e em nutrição seja eficaz, deve incluir a transmissão de informações essenciais sobre saúde como um dos seus pilares, porém, deve ir além, e incluir a abordagem dos valores pessoais, culturais e crenças que apoiam os comportamentos relativos à saúde e alimentação, assim como das normas que valorizam um estilo de vida/hábito alimentar saudável e aspectos práticos, que envolvem o desenvolvimento de habilidades necessárias para a adoção e manutenção de comportamentos relacionados à saúde (Center for Disease Control and Prevention, 2011; Pérez-Rodrigo, Aranceta, 2001).

A Figura 1 mostra como, a partir de um alimento, é possível criar uma rede de conteúdos a serem trabalhados nas disciplinas tradicionais e em atividades extras, permitindo que as questões alimentares e nutricionais sejam desenvolvidas transversalmente, incluindo a participação de todos os atores envolvidos no processo - estudantes, professores, comunidade escolar e família.

Os contos de fada tradicionais abrem inúmeras possibilidades. Em Branca de Neve, parte-se da maçã para se discutirem as outras frutas, sob os aspectos sensoriais e nutricionais (ex: nutrientes, recomendação diária). Atividades complementares como visita à feira e a construção de uma horta escolar permitem que se trabalhem as questões de diversidade, desperdício, sustentabilidade.

A constante consulta da rainha má ao Espelho Mágico abre a possibilidade de se trabalhar o esquema corporal e a percepção da autoimagem. Barker-Sperry e Grauerholtz (2003) avaliaram a valorização do ideal de beleza nos contos de fada e encontraram informações importantes para que estas questões sejam trabalhadas adequadamente com as crianças. Frequentemente, as características de aparência física são mencionadas, sendo que a beleza feminina, sobretudo de mulheres jovens, é a mais ressaltada - em uma história, as autoras encontraram 114 referências de beleza relacionadas à mulher. Também se relaciona beleza com bondade e feiura com maldade, enquanto a beleza é recompensada e sua ausência punida. Dos 168 contos de Grimm estudados por essas autoras, 17\% indicam associação entre a beleza e a inveja, sendo que, em Branca de Neve, a mensagem de rivalidade entre mulheres é clara. Estes achados perpetuam estereótipos e iniquidade entre gêneros, reforçam a exclusão de minorias, e corroboram a mensagem que crianças e adolescentes têm recebido de outras fontes, de que "ser bela" é um fator importante a ser obtido e mantido para se alcançar o sucesso. Ao se utilizarem essas histórias, esses conceitos devem ser desafiados pelos educadores que adotam esses contos como ferramentas, permitindo que sejam reexaminados e reconsiderados.

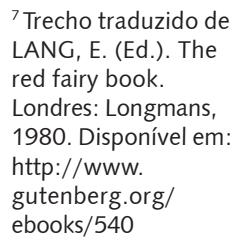


Figura 1. Rede de conteúdos sobre alimentação e nutrição.

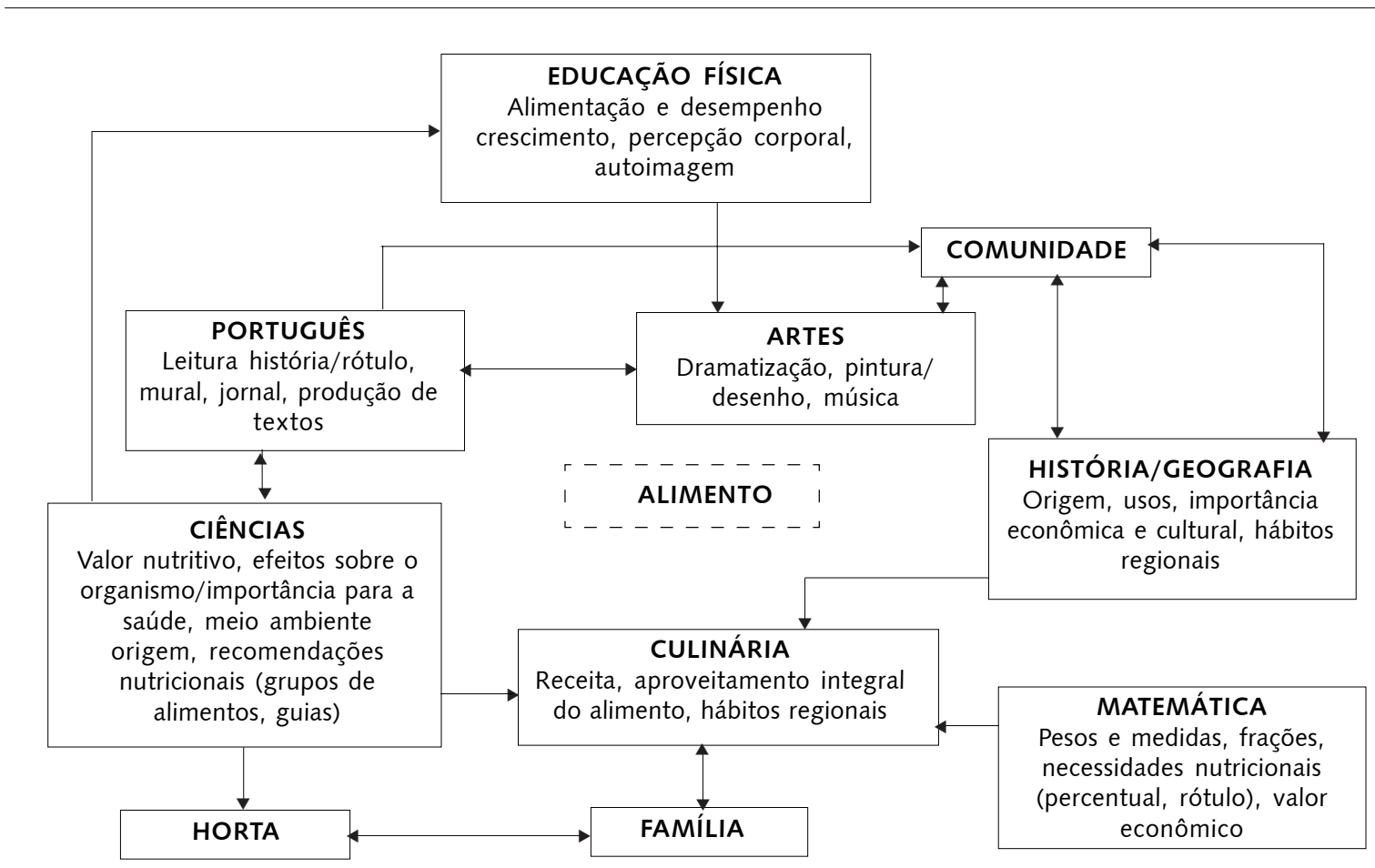

Modificado de Gaglianone, Juzwiak e Perruci (2007).

É importante estar atento ao significado que se quer atribuir às histórias para que não exerçam influência negativa (Lopes, 2010). Por exemplo, um aspecto que deve ser considerado é o de que os contos enfatizam a passividade feminina, reproduzindo e legitimando este status ao gênero femininoem Branca de Neve, isso fica evidente quando os anões passam para ela toda a responsabilidade de cuidar da casa (explicitado, no texto, como: cozinhar, lavar) enquanto os homens estão no trabalho.

A descrição do jantar dos anões, ao chegarem cansados da mina, assim como o banquete de casamento, pode ser usada para discutir a etiqueta às refeições e como experiência para se compartilhar uma refeição, reforçando o papel do alimento como fator de integração social.

Hortaliças são alimentos que aparecem com menor frequência nas histórias (Byrne, Nitzke, 2002) e, segundo a Pesquisa de Orçamentos Familiares 2008-2009, na alimentação do brasileiro também: os resultados indicam que $90 \%$ da população consomem menos do que os quatrocentos $\mathrm{g} / \mathrm{dia}$ de hortaliças e frutas recomendados (Brasil, 2010).

Em Rapunzel, o conto se inicia com o desejo de sua mãe de consumir os nabos do canteiro da vizinha bruxa, o que, ao ser realizado, resulta na preparação de uma salada, que gera excelente oportunidade para ser compartilhada com os alunos. Este conto é um bom exemplo de como os alimentos se apresentam como elementos estruturais em muitas histórias, servindo para justificar o início da ação (Mendo, 2004).

O tema hortaliças nos remete a uma poderosa ferramenta de educação nutricional: a horta. Esta estratégia permite a consolidação da educação integral e por meio do aprendizado coletivo: da criança ao jovem adulto, com a participação de toda a comunidade escolar, é possível promover a alimentação saudável, o cuidado com o meio ambiente, a sustentabilidade e o trabalho em conjunto (Barbosa, 2007). 
Em João e Maria, chama a atenção a situação de carência em que as crianças e seus pais vivem. Por esta razão, a mãe (ou madrasta em algumas versões) convence o pai a deixar as crianças na floresta, aumentando sua chance de sobrevivência. Historicamente, os contos oriundos da tradição medieval oral do povo refletem as inquietações fundamentais do ser humano - medos, frustrações, necessidades - ou seja, podem representar as situações de fome e carência da época a que os camponeses estavam expostos (Mendo, 2004). Certamente, o tema é atual e abre a oportunidade de discussão do Direito Humano à Alimentação Adequada (DHAA), que representa o direito a estar livre de fome e da má nutrição, além do acesso à alimentação adequada. Em seu significado mais amplo, inclui não só a questão do fornecimento de energia e nutrientes, mas, também, de: sua qualidade, segurança sanitária, diversidade, sustentabilidade de práticas produtivas e respeito aos hábitos alimentares culturais. Trabalhar a Educação Alimentar e Nutricional sob a perspectiva do direito humano amplia seu entendimento e constrói a cidadania (Burity et al., 2010; Santos, 2005). Este é um dos contos mais ricos em referências alimentares, e a casa construída de guloseimas e a fartura à mesa representam a voracidade oral; e está clara a mensagem de que ceder à glutonia leva à punição (Mendo, 2004), o que permite a discussão do equilíbrio na alimentação (frequência, quantidade).

A razão da visita de Chapeuzinho à avó é levar alimentos para que fique melhor de sua doença -e oferece uma boa oportunidade para se relacionar a alimentação ao bem-estar e à promoção da saúde; e a caminhada pelo bosque abre a oportunidade de se discutir a importância de um estilo de vida fisicamente ativo.

O Quadro 1 sugere, a partir dos grupos de alimentos definidos no Guia Alimentar para a População Brasileira (Brasil, 2005), quais contos de fada podem ser usados como ponto de partida para o desenvolvimento de conteúdos e atividades em Educação Alimentar e Nutricional.

Quadro 1. Grupos de alimentos, contos tradicionais, conteúdos e atividades

\begin{tabular}{|c|c|c|c|c|}
\hline Grupo de alimentos & $\begin{array}{l}\text { Conto } \\
\text { tradicional }\end{array}$ & $\begin{array}{l}\text { Principal } \\
\text { elemento }\end{array}$ & $\begin{array}{l}\text { Conteúdos e } \\
\text { atividades específicos }\end{array}$ & $\begin{array}{l}\text { Conteúdos } \\
\text { e atividades comuns }\end{array}$ \\
\hline Leguminosas & $\begin{array}{l}\text { João e o pé } \\
\text { de feijão }{ }^{\alpha}\end{array}$ & Feijões & $\begin{array}{l}\text { Produção de alimentos (horta), } \\
\text { sustentabilidade, meio ambiente. }\end{array}$ & \multirow{6}{*}{$\begin{array}{l}\text { Alimentação equilibrada, grupos } \\
\text { de alimentos, alimento-fonte, } \\
\text { variedade. } \\
\text { Aspectos culturais e sociais, } \\
\text { hábitos alimentares, crenças, } \\
\text { tabus, atitudes, tradições, } \\
\text { percepções. } \\
\text { Aspectos sensoriais, degustação. } \\
\text { Composição dos alimentos, } \\
\text { rótulos. } \\
\text { Conservação dos alimentos. } \\
\text { DHAA. } \\
\text { Dramatização. } \\
\text { Higiene pessoal e dos alimentos. } \\
\text { Mecanismo de digestão, } \\
\text { absorção, metabolismo, excreção. } \\
\text { Oficina culinária. } \\
\text { Produção artística. } \\
\text { Produção de alimentos, } \\
\text { sustentabilidade, meio ambiente, } \\
\text { tecnologia. } \\
\text { Produção linguística. } \\
\text { Recomendação diária, porções. } \\
\text { Segurança alimentar e nutricional }\end{array}$} \\
\hline Frutas & $\begin{array}{l}\text { Branca de } \\
\text { Neve }^{f}\end{array}$ & Maçã & $\begin{array}{l}\text { Oficina culinária, visita à feira livre, } \\
\text { aspectos sensoriais, percepção } \\
\text { corporal e autoimagem } \\
\text { (obesidade, transtornos } \\
\text { alimentares, estigma). }\end{array}$ & \\
\hline Hortaliças & Rapunzel $^{ \pm}$ & Nabo & $\begin{array}{l}\text { Oficina culinária, visita à feira livre, } \\
\text { aspectos sensoriais. }\end{array}$ & \\
\hline Leite e derivados & $\begin{array}{l}\text { Cachinhos de } \\
\text { ouros e os } \\
\text { três ursos }\end{array}$ & Mingau & $\begin{array}{l}\text { Industrialização, aleitamento } \\
\text { materno, crescimento, saúde } \\
\text { óssea, importância do desjejum. }\end{array}$ & \\
\hline Carnes e ovos & $\begin{array}{l}\text { Gato de } \\
\text { botas" }\end{array}$ & $\begin{array}{l}\text { Carne de } \\
\text { coelho }\end{array}$ & $\begin{array}{l}\text { Alimentação onívora } x \\
\text { vegetariana, história da } \\
\text { alimentação, cadeia alimentar. }\end{array}$ & \\
\hline $\begin{array}{l}\text { Gorduras, açúcares } \\
\text { e doces }\end{array}$ & João e Maria ${ }^{ \pm}$ & Guloseimas & $\begin{array}{l}\text { Equilíbrio alimentar (quantidade, } \\
\text { frequência do consumo de } \\
\text { alimentos "extras"), desnutrição } \\
\text { x obesidade, saúde dental, DHAA. }\end{array}$ & \\
\hline
\end{tabular}

Autoria/versão atribuída a: " Charles Perrault, ${ }^{ \pm}$Irmãos Grimm, " $\alpha$ Joseph Jacobs, "“ Robert Sothey. 


\section{Considerações finais}

[...] a Literatura não é, como tantos supõe, um passatempo. É uma nutrição. (Meireles, 1979, p.28)

Os contos de fada tradicionais são ferramentas simples que permitem que pais, educadores e nutricionistas explorem inúmeros conceitos sobre alimentação e nutrição de forma lúdica e integrando diversas áreas do conhecimento. Para o sucesso da sua utilização, é importante estabelecer objetivos claros do que se pretende alcançar e adequá-los às habilidades e capacidade de compreensão da criança, respeitando-se seu pensamento mágico e seu desenvolvimento cognitivo.

\section{Referências}

AGUIAR, V.T. (Coord.). Era uma vez... na escola: formando educadores para formar leitores. Belo Horizonte: Formato, 2001.

ALMEIDA, C.G.M. Efeitos de contingências descritas em histórias sobre o comportamento de crianças. 2009. Dissertação (Mestrado) - Universidade Estadual Paulista Júlio de Mesquita Filho, Bauru. 2009.

AVELLAR, G.C.; COUTO, R.C.O. Literatura infantil e a formação do leitor: a utilização dos clássicos adaptados no ensino Fundamental I e II. Dialógica, v.8, n.1, p.27-34, 2009.

AYOB, A. The mixed blessings of Disney's classic fairy tales. Mousaion, v.28, n.2, p.5064, 2010.

BARBOSA, N.S.V. A horta escolar dinamizando o currículo da escola. Caderno 1. Projeto TCP/BRA/3003. Brasília: Organização das Nações Unidas para a Agricultura e Alimentação (FAO), Fundo Nacional de Desenvolvimento da Educação (FNDE) do Ministério da Educação (MEC), 2007.

BARKER-SPERRY, L.; GRAUERHOLTZ, L. The pervasiveness and persistence of the feminine beauty ideal in children's fairy tales. Gender Soc., v.17, n.5, p.711-26, 2003.

BAŞKALE, H. et al. Use of Piaget's theory in preschool nutrition education. Rev. Nutr., v.22, n.6, p.905-17, 2009.

BIRCH, L.L. Development of food acceptance patterns in the first year of life. Proc. Nutr. Soc., v.57, n.4, p.617-24, 1998.

BIZZO, M.L.G.; LEDER, L. Educação nutricional nos parâmetros curriculares nacionais e para o ensino fundamental. Rev. Nutr., v.18, n.5, p.661-7, 2005.

BOOG, M.C.F. O professor e a alimentação escolar. Campinas: Komedi, 2008.

BOWNE, M. A comparative study of parental behaviors and children's eating habits. ICAN: Infant, Child Adolesc. Nutr., v.1, n.1, p.11-4, 2009.

BRASIL. Ministério da Saúde. Secretaria de Atenção à Saúde. Coordenação-Geral da Política de Alimentação e Nutrição. Guia alimentar para a população brasileira: promovendo a alimentação saudável. Brasília: Ministério da Saúde, 2005. (Série A, Normas e Manuais Técnicos). 
BRASIL. Lei 11.947 de 16 de junho de 2009. Dispõe sobre o atendimento da alimentação escolar e do Programa Dinheiro Direto na Escola aos alunos da educação básica; altera as Leis 10.880, de 9 de junho de 2004, 11.273, de 6 de fevereiro de 2006, 11.507, de 20 de julho de 2007; revoga dispositivos da Medida Provisória 2.178-36, de 24 de agosto de 2001, e a Lei 8.913, de 12 de julho de 1994; e dá outras providências. Diário Oficial da União, Brasília, DF, 17 jun. de 2009a. Seção 1, n.113.

. Ministério da Educação. Fundo Nacional de Desenvolvimento da Educação. Resolução/CD/FNDE no 38 de 16 de julho 2009. Dispõe sobre o atendimento da alimentação escolar aos alunos da Educação básica no Programa Nacional de Alimentação Escolar - PNAE. Diário Oficial da União, Brasília, DF, 17 jul. de 2009b. Seção 1, n.135.

Ministério da Saúde. Ministério da Educação. Portaria Interministerial MS/MEC $\overline{n^{\circ} 1010}$ de 08 de maio 2006. Institui as diretrizes para a Promoção da Alimentação Saudável nas Escolas de Educação Infantil, Fundamental e nível Médio das redes públicas e privadas, em âmbito nacional. Diário Oficial da União, Braślia, DF, 09 maio 2006. Seção 1, n.87.

Ministério da Saúde. Ministério do Planejamento, Orçamento e Gestão. Instituto Brasileiro de Geografia e Estatística (IBGE). Pesquisa de orçamentos familiares - POF 2008/2009. Análise do consumo alimentar pessoal no Brasil. Rio de Janeiro: Instituto Brasileiro de Geografia, 2010.

. Ministério da Saúde. Secretaria de Atenção à Saúde. Departamento de Atenção Básica. Manual operacional da alimentação saudável nas escolas. Brasília: Ministério da Saúde, 2008.

BUNN, D. Fatiando as idéias: literatura e alimento. Ómnibus n.27, 2009. Disponível em: <http://www.omni-bus.com/n27/index.html>. Acesso em: 6 jan. 2013.

BURITY, V. et al. Direito humano à alimentação adequada no contexto da segurança alimentar e nutricional. Brasília: ABRHANDH, 2010.

BYRNE, E.M.; NITZKE, A.S. Preeschool children's acceptance of a novel vegetable following exposure to messages in story books. J. Nutr. Educ. Behav., v.34, n.4, p.211-4, 2002.

Nutrition messages in a sample of children's picture books. J. Am. Diet. Assoc., v.100, n.31, p.359-62, 2000.

CENTERS FOR DISEASE CONTROL AND PREVENTION - CDC. Adolescent and school health. Characteristics of an effective health education curriculum. 2011. Disponível em: <http://www.cdc.gov/healthyyouth/sher/characteristics/index.htm>. Acesso em: 06 jan. 2013.

CORDAZZO, S.T.D.; VIEIRA, M.L. A brincadeira e suas implicações no processo de aprendizagem e de desenvolvimento. Estud. Pesqui. Psicol., v.7, n.1, p.89-101, 2007.

CULLEN, K.W. et al. Child reported family and peer influences on fruit, juice and vegetable consumption: reliability and validity measures. Health Educ. Res., v.16, n.2, p.187-200, 2001.

DALLABONA, S.R.; MENDES, S.M.S. O lúdico na educação infantil: jogar, brincar uma forma de educar. Rev. Divulg. Téc.-Cient. ICPG, v.1, n.4, p.107-12, 2004.

DÉGH, L. Grimm's "Household Tales" and its place in the household: the social relevance of a controversial classic. West. Folk., v.38, n.2, p.83-103, 1979.

DELORS, J. et al. Educação: um tesouro a descobrir. Relatório para Unesco, da Comissão Internacional sobre Educação para o século XXI. São Paulo: Cortez, 1999. 
DORAN, R. A critical examination of the use of fairy tale literature with pre-primary children in developmentally appropriate early childhood education and care programs. In: SCHONFIELD, H.; O'BRIEN, S.; WALSH, T. (Eds.). Questions of quality: proceedings of a conference on defining, assessing and supporting quality in early childhood care and education. Dublin: Center for Early Childhood and Development and Education, 2005. p.63-9.

EVERS, C. How to teach nutrition to kids. Portland: Carrot Press, 2003.

GAGLIANONE, C.P.; JUZWIAK, C.R.; PERRUCI, S. (Orgs.). Ideias para promover a alimentação saudável na escola. Santos: Centro Colabrador em Alimentação e Nutrição Escolar, Universidade Federal de São Paulo, 2007.

HOUSTON-PRICE, C. et al. Picture book exposure elicits positive visual preferences in toddlers. J. Exp. Child Psychol., v.104, n.1, p.89-104, 2009.

LAWATSCH, D.E. A comparison of two teaching strategies on nutrition knowledge, attitudes, and food behavior of preschool children. J. Nutr. Educ., v.22, n.3, p.117-23, 1990.

LOPES, E.R.C.C. A importância dos contos de fada na educação infantil: auxiliando na construção da personalidade. In: ENCONTRO DO NÚCLEO DE ENSINO UNESP, 1., 2010, Botucatu. Anais... Botucatu, 2010. 1 cd-rom.

MEIRELES, C. Problemas da literatura infantil. São Paulo: Summus, 1979.

MENDO, E.B. Posibilidades didácticas de los cuentos populares: la importancia de la comida en la narrativa tradicional. In: CONGRESO SOCIEDAD ESPAÑOLA DE DIDÁCTICA DE LA LENGUA Y LA LITERATURA, 8., 2004, Habana. Actas... Habana, 2004. p.165-79. Disponível em: <http://sedll.org/es/admin/uploads/congresos/8/ act/197/barcia_mendo_enrique.pdf >. Acesso em: 6 jan. 2013.

PÉREZ-RODRIGO, C.; ARANCETA J. School based education: lessons learned and new perspectives. Public Health Nutr., v.4, n.1A, p.131-9, 2001.

PIPITONE, M.A.P. et al. Educação nutricional no programa de ciências para o ensino fundamental. Saude Rev., v.5, n.9, p.29-37, 2003.

RODARI, G. La imaginación en la literatura infantil. Imaginaria, v.125, 2004. Disponível em: <http://www.imaginaria.com.ar/12/5/rodari2.htm>. Acesso em: 6 jan. 2013.

SANTOS, L.A.S. Educação alimentar e nutricional no contexto da promoção de práticas alimentares saudáveis. Rev. Nutr., v.18, n.5, p. 681-92, 2005.

SOARES, A.C.F.; LAZZARI, A.C.M.; FERDINANDI, M.N. Análise da importância dos conteúdos da disciplina de educação nutricional no ensino fundamental segundo professores de escolas públicas e privadas da cidade de Maringá - Paraná. Rev. Saúde Pesqui., v.2, n.2, p.179-184, 2009.

TARE, M. et al. Less is more: how manipulative features affect children's learning from picture books. J. Appl. Dev. Psychol., v.31, n.5, p.395-400, 2010. 
O texto apresenta uma reflexão sobre a importância da incorporação de temas de alimentação e nutrição de forma transversal no currículo escolar, relacionados ao cotidiano da criança e garantindo a integração escola-família. Enfatiza-se a importância da adoção de estratégias adequadas à faixa etária e sugere-se que os contos de fada tradicionais sejam usados como ferramenta para o desenvolvimento de conteúdos e atividades que vão além das questões nutricionais e incluam, também, questões culturais, sociais, ambientais e sensoriais.

Palavras-chave: Educação alimentar e nutricional. Nutrição. Literatura infantil. Leitura.

\section{Once upon a time... An insight on the use of fairy tales} as a tool for food and nutrition education

The text presents a reflection on the importance of incorporating food and nutrition themes transversally in the school curricula, related to the child's quotidian and guaranteeing the school-family integration. The importance of selecting ageappropriate strategies is emphasized and traditional fairy tales are suggested as a tool for the development of contents and activities that go beyond nutritional issues and include cultural, environmental and sensorial aspects as well.

Keywords: Food and nutrition education. Nutrition. Juvenile literature. Reading.

Érase una vez...una mirada sobre el uso de los contos de hada como herramienta para la educación alimentaria y nutricional

El texto presenta una reflexión sobre la importancia de la incorporación de los temas de alimentación y nutrición transversalmente en el currículo escolar, relacionados al cotidiano del niño y garantizando la integración escuela-familia. Enfatizase la importancia de seleccionar estrategias adecuadas a la edad de los niños y los contos tradicionales de hadas son sugeridos como herramienta para el desarrollo de contenidos y actividades que ultrapasen las cuestiones biológicas y nutricionales y incluyan además, cuestiones culturales, sociales, ambientales y sensoriales.

Palabras clave: Educación alimentaria y nutricional. Nutrición. Literatura infanto-juvenil. Lectura.

Recebido em 13/03/12. Aprovado em 21/12/12 